\title{
Stress relacionado ao trabalho no Brasil: da dimensão empírica à determinação social
}

\author{
Diego de Oliveira Souza \\ Enfermeiro, especialista em Saúde do Trabalhador, mestre e doutor em Serviço Social. Docente da \\ Universidade Federal de Alagoas (Ufal), lecionando no Programa de Pós-Graduação em Ensino e Formação de \\ Professores (PPGEFOP), no Programa de Pós-Graduação em Serviço Social (PPGSS) e na graduação em \\ Enfermagem \\ diego.souza@arapiraca.ufal.br
}

Recebido em 10 de setembro de 2021

Aceito em 23 de novembro de 2021

\begin{abstract}
Resumo:
Com o objetivo de analisar as múltiplas facetas do stress relacionado ao trabalho no Brasil, foi elaborada essa pesquisa teórica, em três etapas metodológicas: levantamento estatístico sobre stress entre 2008 e 2017, a partir de dados da Dataprev; revisão integrativa do período de 2017 a 2019, com a combinação dos descritores stress AND occupational health na Biblioteca Virtual da Saúde; e problematização teórico-filosófica sobre a determinação social do stress no trabalho, baseado no materialismo histórico-dialético. Os dados da Dataprev revelam uma tendência de aumento do stress relacionado ao trabalho no período estudado. Na revisão, constatou-se predominância no setor de serviços, em especial, na saúde. Sobre a determinação social, considerou-se a correlação dos elementos estressores e as metamorfoses do complexo do trabalho face à crise estrutural do capital. Nessa esteira interpretativa, partimos do stress como mediação para pensar, mais amplamente, a saúde mental dos trabalhadores, inclusive ratificando a eminência dessa mediação ante o conjunto que compõe. A nota reflexiva final consiste em apreender um outro componente desse prolixo mosaico, qual seja: o desmonte e a fragilização dos serviços públicos de saúde. A tragédia da saúde mental dos trabalhadores brasileiros se manifesta, portanto, pelo menos, em duas faces: de um lado, a degradação da saúde mental pelo trabalho e, doutro, a exponenciação por conta da fragilização das políticas de saúde no Brasil.

Palavras-chave: Saúde mental, saúde do trabalhador, stress, trabalho, transtornos relacionados a trauma e fatores de estresse.

\section{Work-related stress in Brazil: from the empirical dimension to social determination}

\begin{abstract}
:
In order to analyze the multiple facets of work-related stress in Brazil, this theoretical research was designed in three methodological steps: statistical survey on stress between 2008 and 2017, based on Dataprev; integrative review of the period 2017 to 2019, with the combination of the descriptors stress AND occupational health in the Virtual Health Library; and theoretical-philosophical study on the social determination of work-related stress, based on historical-dialectic materialism. Dataprev reveals a trend of increasing work-related stress in the period studied. In the review, there was a predominance in the service sector, especially in health. Regarding social determination, the correlation of stressors and the metamorphosis of the labour complex in the face of the structural capital crisis was considered. In this interpretative track, we start from stress as a mediation to think, more broadly, about the mental health of workers, even ratifying the eminence of this mediation in view of the set that it is composed of. The final reflective note consists in apprehending another component of this prolix mosaic, which is: the dismantling and weakening of public health services. The tragedy of the mental health of Brazilian workers manifests itself, therefore, in at least two faces:
\end{abstract}


on one side, the degradation of mental health through work, and on the other, the exponentiation due to the weakening of health policies in Brazil.

Keywords: Mental health, occupational health, work, trauma and stressor related disorders.

\section{El estrés laboral en Brasil: de la dimensión empírica a la determinación social}

\section{Resumen:}

Para analizar las múltiples facetas del estrés laboral en Brasil, esta investigación teórica se desarrolló en tres etapas metodológicas: búsqueda estadística sobre el estrés entre 2008 y 2017, a partir de los datos de Dataprev; revisión integradora del período de 2017 a 2019, con la combinación de los descriptores stress AND occupational health en la Biblioteca Virtual de Salud; y problematización teórico-filosófica sobre la determinación social del estrés laboral, a partir del materialismo históricodialéctico. Los datos de Dataprev revelan una tendencia al aumento del estrés laboral en el periodo estudiado. En la revisión, se encontró un predominio en el sector de los servicios, especialmente en la salud. En cuanto a la determinación social, se consideró la correlación de los elementos de tensión y la metamorfosis del complejo laboral frente a la crisis estructural del capital. En esta vía interpretativa, partimos del estrés como mediación para pensar, más ampliamente, en la salud mental de los trabajadores, ratificando incluso la eminencia de esta mediación ante el conjunto que conforma. El último apunte reflexivo consiste en aprehender otro componente de este prolijo mosaico, que es: el desmantelamiento y debilitamiento de los servicios sanitarios públicos. La tragedia de la salud mental de los trabajadores brasileños se manifiesta, por tanto, en al menos dos vertientes: por un lado, la degradación de la salud mental por el trabajo y, por otro, la exponenciación debido al debilitamiento de las políticas sanitarias en Brasil.

Palabras clave: Salud mental, salud laboral, estrés, trabajo, trastornos relacionados con el trauma y factores de estrés.

\section{INTRODUÇÃo}

Embora a seara dos fenômenos psicoemocionais seja de difícil delimitação e, por consequência, também de definição, podemos dizer que o stress psicológico se caracteriza por um conjunto de respostas do indivíduo ante um estímulo que o leve à excitação emocional, variando de irritabilidade pontual à depuração da capacidade de se adaptar (MARGIS et al., 2003).

A variabilidade da natureza dos elementos estressores também deve ser considerada, como, por exemplo, "as exigências de uma determinada situação e os recursos do indivíduo, ao nível biológico, psicológico ou de sistemas sociais" (SANTOS; CASTRO, 1998, p. 677). As mediações de tais situações podem ser engendradas nos processos particulares de trabalho, mas se entrelaçam com os elementos da reprodução social (SOUZA; MELO; VASCONCELLOS, 2015). 
É nesse prisma que se tem constatado conexões entre a saúde mental e a exploração da força de trabalho (SOUZA; MELO; VASCONCELLOS, 2015), mas também com outras particularidades desse processo, a exemplo da divisão/hierarquização do trabalho, questão de gênero, desigualdades étnicas ou regionais (AREIAS; GUIMARÃES, 2004; FARO; PEREIRA, 2011; ORGANIZAÇÃO MUNDIAL DA SAÚDE, 2015).

Essa processualidade social acaba por transbordar em nível individual, sobretudo com as diferentes reações em face dos elementos estressores, reações estas que variam do alarme à exaustão, frequentemente causando transtornos de adaptação. Tanto é que esses transtornos têm sido descritos, tanto em termos clínicos quanto epidemiológicos, de modo combinado ao stress (SANTOS; CASTRO, 1998, p. 677).

Nessa pesquisa, debruçamo-nos sobre esse agravo, com o objetivo de analisar, dialeticamente, suas múltiplas facetas (das mais superficiais às mais profundas) no Brasil contemporâneo. Isso implica uma aproximação inicial com as formas genéricas do processo se comportar empiricamente, depurar suas mediações mais eminentes (quem vive o processo, algumas causas e consequências) e, sobretudo, alcançar os elementos mais profundos de sua determinação social, em face do processo histórico recente.

\section{METODOLOGIA}

Trata-se de uma pesquisa teórica, pois busca contribuir para a (re)formulação de um viés teórico de entendimento do processo social tomado como objeto de estudo. Possui caráter analítico-reflexivo e exploratório, fazendo uso dos procedimentos de pesquisa documental e bibliográfica. Com esses procedimentos, apreendemos as mediações empíricas necessárias à reflexão teórica posterior, de caráter ontológico, uma vez que se preocupa com as determinações genérico-essenciais da problemática em xeque, sem ignorar suas particularidades, sobretudo em face da realidade brasileira, entre 2008 e 2017.

A pesquisa se constituiu com base na postura metodológica marxiana, porquanto apreende uma relação entre ciência e realidade na qual a regência é da realidade. Trata-se do princípio seminal do materialismo dialético (logo, histórico), uma vez que a partir dele se 
constata a reciprocidade da relação de determinação entre a esfera material (a realidade em si) e o mundo das ideias, mas com prioridade ontológica para a esfera material (TONET, 2013).

Nessa postura teórico-metodológica, o sujeito (enquanto persofinicação particular da esfera subjetiva) não escolhe a priori um método "na estante científica dos métodos" a fim de investigar um objeto de estudo (particularidade da esfera material), recortado a seu bel prazer. Ao contrário, o objeto é o polo regente do processo de conhecimento, expressando a prioridade da esfera material sobre o mundo das ideias, embora o sujeito seja completamente ativo no processo (LUKÁCS, 2012; TONET, 2013).

A postura de aproximação do sujeito para com o objeto se efetiva a partir daquela dimensão mais acessível, à qual poderíamos chamar de esfera aparente, que, em geral, é passível de tradução (em parte) por meio de um conjunto de dados empíricos. Todavia, nem esses dados empíricos são suficientes para um movimento de conhecimento mais profundo do objeto, nem podem ser ignorados, sob o risco de cair na armadilha filosófica que separa essência da aparência e a esta última atribui o caráter de falseamento da realidade (LESSA, 1999).

A aproximação inicial com o objeto, ainda que na sua esfera fenomênica, deve originar uma série de questões que nortearão o sujeito cognoscente, lançando mão de estratégias diferentes a depender do aspecto do objeto que se anuncia como relevante às respostas de tais questões. Diríamos que se trata de um caminho de duas vias, ida e volta (LUKÁCS, 2012), quando o sujeito, inicialmente, aproxima-se do objeto e, nesse momento, apenas pode desconstruí-lo desde sua superfície. Posteriormente, com sucessivas aproximações com o objeto, cada vez mais profundas, pode-se reconstruí-lo, guiando-se pela história e dando passos rumo à esfera mais essencial do objeto em si.

Esse caminho, que pressupõe sucessivas articulações entre o universal e o particular, foi descrito por Karl Marx apenas brevemente em "Contribuição à crítica da economia política" (MARX, 2008), mas se faz eminente no conjunto da sua obra. No próprio "O Capital" (MARX, 1988a, 1988b), obra máxima de Marx, o pensador alemão toma, como ponto de partida, as relações mais imediatas da sociedade capitalista, as que se revelam com maior evidência aos sujeitos, quais sejam: as trocas generalizadas de mercadorias. 
Com isso, Marx precisava caracterizar a esfera mais superficial do seu objeto de estudo, também trazendo dados empíricos, consoante comparecem ao longo de sua obra, a exemplo dos dados econômicos, relatórios de inspetores sanitários nas fábricas e outras estatísticas sociais, sobretudo da Inglaterra. Porém, o ponto fulcral do raciocínio marxiano é, a partir dessa esfera fenomênica, desenvolver uma retrodução histórica, apreendendo as tensões, conflitos, relações e tendências mais gerais que explicam o seu objeto de estudo.

Postura semelhante adotou Friedrich Engels em "A situação da classe trabalhadora na Inglaterra" (ENGELS, 2008), quando o autor articulou a apreensão de dados empíricos de Londres e Manchester (sobre urbanização, saneamento, moradia, estado nutricional, adoecimento etc.) com concatenações que demandaram a recuperação da história na reconstrução do objeto de estudo, avançando em direção à esfera essencial da realidade investigada.

Considerando esse conjunto de premissas e tendo em vista os limites de um artigo, propomos três etapas de investigação: 1) a aproximação com a dimensão empírica do stress relacionado ao trabalho, a partir de dados estatísticos; 2) uma revisão integrativa com vistas ao diálogo ante o que foi produzido, mais recentemente, sobre o objeto aqui estudado; 3) uma análise teórico-filosófica que nos conduza a um caminho de volta, colocando o objeto de estudo em novos termos.

Iniciamos com a etapa estatística, a partir de dados secundários coletados no website da Dataprev, em seus Anuários Estatísticos, mais especificamente no capítulo sobre acidentes de trabalho. Destacamos que cada Anuário apresenta dados dos últimos três anos, atualizando os números dos dois anos anteriores ao seu ano de referência. Com isso, iniciamos nossa coleta a partir do Anuário de 2010, pois nele há os dados mais atuais de 2008 e assim sucessivamente, até o Anuário de 2017, o mais atual por ocasião da coleta.

Os dados coletados compuseram uma série histórica de 2008 a 2017, considerando a ocorrência do agravo descrito como "reação ao stress grave e transtorno de adaptação" (código F43 na CID-10). Esse agravo está relacionado a acontecimentos estressantes cuja trama causal contém forte influência do trabalho e, para fins das notificações no âmbito 
previdenciário, pode ser adotado como referência para os casos de stress relacionado ao trabalho, ainda que não de forma representativa da totalidade dos casos.

Para transformar a ocorrência do referido agravo em taxa de incidência, consideramos sua divisão pela população economicamente ativa referenciada pela Dataprev, padronizandoos para um coeficiente por 100.000. Não foi nossa intenção realizar um estudo epidemiológico ou uma análise estatística dos dados, mas apenas trazê-los como ponto de partida da nossa análise, problematizando-os à luz do processo histórico-social.

Em relação à revisão integrativa, realizamos uma busca via Biblioteca Virtual da Saúde (BVS), utilizando os descritores stress e occupational health, combinados pelo operador booleano and. Aplicamos os seguintes filtros: texto completo; Brasil em país/região como assunto, artigo como tipo de documento; idiomas inglês, português e espanhol; e 2017 a 2019 como período de publicação. Foram excluídos os artigos duplicados, editoriais, cartas, comunicações breves ou que não se relacionavam às seguintes questões norteadoras: quem são os sujeitos acometidos pelo stress ocupacional? Quais os fatores estressores? Quais as estratégias de enfrentamento?

Convém esclarecer que a revisão foi a mediação entre a abordagem mais quantitativa e a reflexão analítica em construção no processo, em uma transição que trouxe o estado da arte para aparar algumas arestas das estatísticas nacionais. As questões levantadas em face dos dados coletados e dos achados dos estudos revisado serviram de escopo analítico para a reflexão teórico-filosófico exposta na terceira etapa. Dialogamos com autores marxistas contemporâneos para explicar o processo de determinação social da saúde mental, em particular do stress, na contemporaneidade. Dialogamos com a sociologia do trabalho e com as categorias teóricas da Saúde do Trabalhador, como cargas de trabalho, processo de desgaste e sofrimento. Por fim, fizemos uma articulação do stress com a saúde mental de modo mais amplo, inclusive voltando aos números para fazer ilustrações dessa dinâmica universalparticular. 


\section{ALGUMAS NOTAS SOBRE A DIMENSÃO EMPÍRICA DO STRESS RELACIONADO AO TRABALHO}

Os dados sobre o stress revelam um aumento na ocorrência desse agravo e, também, no seu coeficiente de incidência ao longo da série 2008 - 2017, consoante a Tabela 1.

Tabela 1 - Ocorrência e taxa de incidência de reações graves ao stress e transtornos de adaptação, 2008 - 2017, Brasil.

\begin{tabular}{cccccc}
\hline Ano & $\begin{array}{c}\text { Ocorrência } \\
(\mathrm{N})\end{array}$ & $\begin{array}{c}\text { Incidência } \\
\text { (por 100.000) }\end{array}$ & Ano & Ocorrência (N) & $\begin{array}{c}\text { Incidência } \\
\text { (por 100.000) }\end{array}$ \\
\hline 2008 & 7.119 & 7,15 & 2013 & 9.121 & 8,82 \\
2009 & 6.412 & 6,34 & 2014 & 9.078 & 9,14 \\
2010 & 6.002 & 6,42 & 2015 & 11.118 & 11,01 \\
2011 & 6.482 & 6,47 & 2016 & 11.031 & 10,76 \\
2012 & 7.892 & 7,82 & 2017 & 9.767 & 9,34 \\
\hline
\end{tabular}

Fonte: elaborada pelo autor a partir de dados da Dataprev.

Embora haja oscilações na taxa de incidência, com queda no segundo ano da série em relação ao primeiro, nos sete anos seguintes há aumento ininterrupto da taxa (2009 a 2015), apresentando leve queda em 2016 e, novamente, em 2017. Apesar da discreta oscilação para menos, o patamar dos últimos quatro anos está compreendido entre 9 e 11 por 100.000 habitantes, consideravelmente maior que as taxas de 6 ou 7 do início da série.

Com isso, temos uma ideia da proporção que esse agravo vem tomando na saúde da classe trabalhadora, mesmo que os dados deixem escapar uma parcela significativa de trabalhadores (informais, invisíveis às análises previdenciárias) e que a quantidade de anos observada não seja suficiente para conclusões taxativas.

Vale destacar que o Centro Colaborador de Vigilância dos Agravos à Saúde do Trabalhador - CCVISAT (2019) da Universidade Federal da Bahia (UFBA) fez levantamento semelhante, publicado no seu boletim. O CCVISAT (2019) contabilizou 8.474 notificações de reações graves ao stress e transtorno de adaptação entre 2006 e 2017, número inferior aos 
dados da maioria dos anos, isoladamente, da série que analisamos, sendo superior apenas aos valores registrados em 2009, 2010, 2011 e 2012 (ver tabela 1); e bem inferior ao total da série deste artigo $(\Sigma(\mathrm{N})=84.022)$. A diferença se dá, em especial, pela fonte da coleta dos dados, pois enquanto nos baseamos em dados da Previdência Social, os dados do CCVISAT são do Sistema de Informação de Agravos de Notificação (SINAN).

Acreditamos que ambos os caminhos (seja pelo DATAPREV, seja pelo SINAM) sejam válidos para o debate. Pelo SINAM, há a chance de uma notificação de caráter mais amplo, pois pode-se incluir trabalhadores informais. Contudo, no âmbito genérico (no qual se situa o SINAM) nem sempre se visibiliza a busca pela relação das doenças ou transtornos com o trabalho, uma vez que a especificidade de questões trabalhistas e/ou previdenciárias não estão em foco. Tanto é que os números foram inferiores na pesquisa do CCVISAT em relação aos apresentados aqui. Já o DATAPREV deixa escapar os trabalhadores precarizados/informais, mas coaduna as notificações via Comunicado de Acidente de Trabalho (CAT), sendo, portanto, específica sobre agravos relacionados ao trabalho. Para o caso aqui analisado, os dados do DATAPREV, ainda que possuam insuficiências, apresentounos uma dimensão empiricamente relevante do agravo em xeque.

Assim, até aqui, o processo de aproximação com o objeto analisado permitiu afirmar que se trata de um problema de saúde que vem se agravando ao longo dos últimos anos, com relevância em levantamentos estatísticos, mesmo que haja subnotificação. Porém, os dados nos anuários da Previdência Social apresentam limites no que concerne ao detalhamento de variáveis associadas ao tipo de acidente/doença por código da CID-10. Embora se tenha dados por idade, ocupação, região, estado ou município para o conjunto das notificações, não é apresentada essa estratificação quando se trata das notificações específicas por código da CID10. Ante essa ausência, precisamos entender, sobretudo, quem são os trabalhadores que têm sofrido com o stress. Além disso, torna-se necessário conhecer os elementos estressores, as consequências e as estratégias de enfrentamento. Por conta disso, recuperamos o estado da arte mais atual, conforme apresentado a seguir. 


\section{PARA ENTENDER AS MANIFESTAÇÕES GERAIS DO STRESS RELACIONADO AO TRABALHO: ESTADO DA ARTE}

A busca na BVS retornou 17.938 resultados, sendo que, após a aplicação dos filtros, restaram 121 publicações. Na etapa de triagem, seguimos com a leitura dos títulos e resumos, excluindo aqueles que não se relacionavam às questões norteadoras da revisão. Com isso, o resultado obtido foi de 16 artigos. Entretanto, ainda foram excluídas as publicações duplicadas e as do tipo revisão integrativa, editorial, carta e comunicação breve, o que definiu a amostra final em 12 artigos.

Entre as publicações revisadas, oito utilizaram abordagem quantitativa transversal (SANTANA SILVA; LEITE RIOS; FRANÇA-BOTELHO, 2017; GEREMIAS et al., 2017; LLAPARODRIGUEZ et al., 2018; RIBEIRO et al., 2018; LOPES; SILVA, 2018; FADEL et al., 2019; PASQUALUCCI et al., 2019; BARROS-DELBEN et al., 2019; MUNIZ et al., 2019), sendo que uma delas (FADEL et al., 2019) articulava essa abordagem a outra, de natureza qualitativa. Duas pesquisas foram estudos quase-experimentais (PIZUTTI et al., 2019; JACQUES et al., 2018) e uma apresentou abordagem apenas qualitativa (FERREIRA et al., 2017).

A maioria dos artigos revelou que as mulheres são as mais acometidas pelo stress relacionado ao trabalho (SANTANA SILVA; LEITE RIOS; FRANÇA-BOTELHO, 2017; FERREIRA et al., 2017; LLAPA-RODRIGUEZ et al., 2018; RIBEIRO et al., 2018; LOPES; SILVA, 2018; FADEL et al., 2019; MUNIZ et al., 2019; PIZUTTI et al., 2019), tendo sido os homens os mais acometidos apenas em 4 publicações (GEREMIAS et al., 2017; JACQUES et al., 2018; PASQUALUCCI et al., 2019; BARROS-DELBEN et al., 2019). Em relação à idade, os estudos, em sua maioria, apresentaram médias compreendidas entre 30 e 48 anos (FERREIRA et al., 2017; SANTANA SILVA; LEITE RIOS; FRANÇA-BOTELHO, 2017; GEREMIAS et al., 2017; RIBEIRO et al., 2018; LOPES; SILVA, 2018; JACQUES et al., 2018; FADEL et al., 2019; BARROS-DELBEN et al., 2019), mas dois estudos apresentaram média de idade mais baixa (28 anos) (PASQUALUCCI et al., 2019; PIZUTTI et al., 2019). Revelou-se, ainda, categorias profissionais expostas aos elementos estressores, conforme apresentamos na sequência.

Em relação ao trabalho de docentes em uma universidade, verificou-se que o stress esteve presente em $35 \%$ da amostra, sobretudo associado às questões administrativas e à relação estabelecida com os discentes (FADEL et al., 2019). Em outro estudo, o stress esteve 
mais presente entre os servidores de menor escolaridade (geralmente, técnicosadministrativos) e associado à falta de estrutura de trabalho e ao baixo apoio social recebido (LOPES; SILVA, 2018).

Quando se trata do trabalho em saúde, foi constatado que 17,7\% de médicos residentes apresentaram sintomas de stress e 63\%, quadros compatíveis à Síndrome de Burnout associada ao stress (PASQUALUCCI et al., 2019). Já entre estudantes de odontologia, o stress aumenta quando se avança à fase clínica do curso, quando há atendimento à população (MUNIZ et al., 2019).

Em análise comparativa entre trabalhadores da Enfermagem e da Medicina de um hospital universitário, revelou-se que aqueles estão sob maior stress, sobremaneira associado ao menor controle do trabalho e ao baixo apoio social (RIBEIRO et al., 2018). Outra análise comparativa envolvendo a Enfermagem também revelou maior stress entre as enfermeiras quando comparadas aos advogados, com $55 \%$ e 30,9\% de presença de stress, respectivamente (SANTANA SILVA; LEITE RIOS; FRANÇA-BOTELHO, 2017).

A Enfermagem aparece com destaque entre as atividades mais investigadas. Em estudo com 101 trabalhadores dessa área em um hospital universitário, revelou-se que 43\% dos elementos analisados do processo de trabalho são estressores, sobretudo aqueles relacionados à organização (MUNIZ et al., 2019). Corroborando, em investigação qualitativa sobre a visão de enfermeiros sobre fatores desencadeadores de stress e estratégias de enfrentamento, identificou-se que, entre os fatores causais, estavam a sobrecarga de trabalho, condições de trabalho precárias, prazos curtos para o cumprimento das atividades e conflitos nas relações interpessoais (FERREIRA et al., 2017).

Visando constituir estratégias de enfrentamento aos estressores, em um estudo de caráter quase-experimental, foi realizada uma intervenção por meio de sessões de cuidados estéticos, relaxamento e palestras. 60 enfermeiros participaram desse estudo, mas não houve associações estatísticas significativas para a redução dos estressores (JACQUES et al., 2018). Em outro estudo quase-experimental, trabalhadores da saúde participaram do programa Mindfulness for Stress, desenvolvido através de cursos. Escalas de análise de sintomas de vários problemas da esfera psicoemocional foram aplicadas antes e depois do programa, revelando que a intervenção de grupo foi viável para melhorar a saúde mental dos trabalhadores 
(PIZUTTI et al., 2019). Já na pesquisa qualitativa, os enfermeiros mencionaram o apoio social e familiar e as atividades de lazer como as principais estratégias que contribuem no enfrentamento do stress (FERREIRA et al., 2017).

Fora do setor saúde, além dos servidores de universidades e advogados, houve o caso dos bancários. Na identificação de relação entre diabetes melitos e stress nesses trabalhadores, constatou-se que 91,69\% dos homens tinham a glicemia de jejum alterada, assim como 58,33\% apresentavam stress. Entre as mulheres, o percentual foi de 75 tanto para alteração na glicemia quanto para stress (GEREMIAS et al., 2017).

Por fim, entre militares e civis integrantes de uma expedição no programa Antártico Brasileiro (PROANTAR), houve investigação mais detida aos elementos estressores, com destaque para a prevalência, nesta ordem, dos estressores ambientais $(60,71 \%)$, ocupacionais $(23,80 \%)$ e interpessoais $(15,47 \%)$ no início do Programa; e de estressores interpessoais $(55,97 \%)$, ambientais $(32,08 \%)$ e ocupacionais $(11,94 \%)$ ao final (BARROS-DELBEN et al., 2019).

Como se pode ver, a saúde foi o setor mais afetado quando nas pesquisas sobre o stress, sobremodo a Enfermagem. Mas as atividades analisadas possuem a característica comum de se desenvolverem na seara dos serviços, principalmente com atendimento ao público. A atividade mais diferenciada consistiu na expedição à Antártica, mas mesmo nesta, com o desenrolar das atividades, as relações interpessoais passaram a ser mais estressoras do que os elementos ambientais.

Essa característica nos leva a presumir que, nesse processo de interrelação com o público ou com os colegas de trabalho, sejam engendrados elementos estressores, sobretudo quando faltam condições estruturais ou apoio social. Esses elementos se mostraram mais intensos para algumas categorias profissionais (na Enfermagem ou entre servidores de menor escolaridade nas universidades) ou para o gênero feminino.

Com base nessas particularidades, emergiram reflexões sobre como elas se conectam entre si e com a totalidade social: como se configura o mundo do trabalho hoje e como ele se relaciona com essas particularidades? Como se dá o processo de determinação dos elementos estressores no trabalho? São questões que nos lançam em direção à análise sequente. 


\section{À DETERMINAÇÃO SOCIAL DO STRESS E DE VOLTA AOS NÚMEROS}

Considerando a tendência crescente do stress relacionado ao trabalho e voltando-se aos aspectos mais comuns entre aqueles trabalhadores mais acometidos, o processo de determinação social desse fenômeno se explica nas (e partir das) recentes mudanças no complexo do trabalho, sobretudo a partir da década de 1970.

Alguns autores já se dedicaram à correlação do stress com as referidas mudanças, a exemplo de Pinto (2010) e Alves (2010) ao afirmarem que a nova forma de organizar o trabalho lança mão de um sistema de gerência pelo stress. Isto porque, ao contrário da rigidez do modelo de organização que predominava anteriormente (baseado no binômio taylorismo/fordismo), a organização do trabalho pela flexibilização pressupõe a polivalência e a organização de teams atuando em células, sendo que cada uma dessas é responsabilizada pelo cumprimento de metas estabelecidas, decidindo-se, no interior da própria equipe, a distribuição das tarefas entre os seus membros.

Alves (2005) vai além, cunha a expressão “novo (e precário) mundo do trabalho" para explicar as transformações em curso, com intensas reverberações para a saúde, a exemplo do stress. Para o autor, a polivalência e as constantes mudanças em relação ao que se fazer e como se fazer geram crises de adaptabilidade, expressas, cada vez mais, nos indicadores de saúde.

Uma questão decisiva a partir de tal correlação consiste em saber: quais os fundamentos das recentes transformações no complexo do trabalho? Sobre isso, é preciso considerar a argumentação de Mészáros (2009), uma vez que o filósofo húngaro demonstra que as transformações na esfera produtiva consistem em tentativa de o capital se reconfigurar em face de sua crise estrutural.

A crise que se anunciou a partir da década de 1970 é resultado da dinâmica expansiva e anárquica do sistema do capital, expressa, fundamentalmente, na tendência perene de queda relativa na taxa de lucros. O estopim desse processo levou o sistema aos seus limites absolutos, a partir daí sendo incapaz de se reinventar com as crises cíclicas, até então características da dinâmica capitalista. Em vez disso, estabeleceu-se uma crise global, que atingiu todos os complexos do ser social e desenvolveu-se de modo rastejante em vez de 
violento e crônico em vez de agudo, embora possa ter, em seu interior, ciclos próprios, com maior violência (MÉSZÁROS, 2009).

As respostas do capital à sua crise se dão a partir da reconfiguração produtiva, cuja acumulação flexível é ponto nodal; da hipertrofia da esfera financeira, decisiva para gerar a sensação de recuperação das taxas de lucro, mesmo que através da especulação sobre produções futuras; e da neoliberalização do Estado, viabilizando a efetivação tanto da financeirização quanto da reconfiguração produtiva (MÉSZÁROS, 2009).

No que tange, especificamente, a reconfiguração produtiva, destacam-se as alterações do complexo do trabalho, aqui já mencionadas, mas em que se pode acrescentar os processos de automação, com um rápido avanço da microeletrônica (ANTUNES, 2015) e, no último anos, da indústria 4.0 (FONTES, 2017), inclusive gerando previsões teóricas de "adeus ao trabalho", como se o trabalho humano fosse plenamente substituível pela tecnologia. Entre outros autores, Antunes (2015) demonstrou que o suposto adeus é inconcebível na lógica do capital, tal qual Marx (1988a) já havia comprovado quando revelou que não há produção de valor sem a força de trabalho.

O que tem ocorrido, portanto, é um aumento da produtividade, com uma composição orgânica do capital na qual seu componente constante (o valor dos meios de produção) cresce relativamente sobre seu componente variável (o valor da força de trabalho), conforme desde sempre, no capitalismo, só que agora em uma velocidade nunca experimentada e mundializada. Para Chesnais (2001), a mundialização do capital trouxe consigo uma hierarquização internacional na divisão de trabalho, na qual determinadas formas de trabalho, com o emprego maior da força de trabalho em sua forma tradicional, foram deslocadas para nações desfavorecidas nessa hierarquia. Além disso, registre-se que, com a acumulação flexível, também houve o aumento da força de trabalho no setor de serviços, inclusive nas nações de capitalismo avançado (MÉSZÁROS, 2009; ALVES, 2010). Ou seja, o capital não pode prescindir do trabalho e não houve, portanto, adeus ao trabalho, mas seu metamorfoseamento.

Um elemento decisivo dessa metamorfose está na capacidade de captura da subjetividade dos trabalhadores, convencendo-os de que as metas de produtividade da 
empresa são suas e, assim, tornando obsoleta a rigidez da gerência tradicional. Para Alves (2005), o cerne para o aumento do adoecimento mental sem precedentes está nessa captura, sobremaneira pelas promessas fadadas ao fracasso que emulam a subjetividade dos trabalhadores, ante um processo de competição que não pode resultar, senão, em poucos vencedores e muitos derrotados.

Com a reconfiguração produtiva, o processo de desgaste e sofrimento mental dos trabalhadores atinge o seu ápice, sendo a principal marca da questão da saúde dos trabalhadores na contemporaneidade (SOUZA, 2019). Acrescentaríamos que o stress relacionado ao trabalho é umas das expressões particulares mais eminentes no bojo desse ápice, senão a maior, em termos quantitativos. Os dados da Tabela 2 contribuem para essa reflexão, uma vez que se observa a posição particular do stress diante dos principais agravos do âmbito psicoemocional.

Tabela 2 - Ocorrência das notificações dos quatros principais agravos de saúde mental no trabalho (códigos na CID-10), 2008 - 2017, Brasil.

\begin{tabular}{cccccc}
\hline Ano & F43 & F32 & F41 & F33 & Total \\
\hline 2008 & 7.119 & 5.205 & 1.923 & 1.001 & 15.248 \\
2009 & 6.412 & 4.908 & 2.482 & 1.193 & 14.995 \\
2010 & 6.002 & 4.116 & 2.366 & 1.049 & 13.533 \\
2011 & 6.482 & 3.957 & 2.508 & 983 & 13.930 \\
2012 & 7.892 & 3.628 & 2.741 & 1.060 & 15.321 \\
2013 & 9.121 & 3.935 & 3.196 & 1.150 & 17.402 \\
2014 & 9.078 & 3.634 & 3.195 & 1.104 & 17.011 \\
2015 & 11.118 & 2.797 & 2.900 & 973 & 17.788 \\
2016 & 11.031 & 2.715 & 3.066 & 913 & 17.725 \\
2017 & 9.767 & 2.396 & 3.115 & 832 & 16.110 \\
\hline Total & $\mathbf{8 4 . 0 2 2}$ & $\mathbf{3 7 . 2 9 1}$ & $\mathbf{2 7 . 4 9 2}$ & $\mathbf{1 0 . 2 5 8}$ & $\mathbf{1 5 9 . 0 6 3}$
\end{tabular}

Fonte: Elaborada pelo autor a partir de dados da Dataprev. Códigos CID-10: F43 - reação grave ao stress e transtorno de adaptação; F32 - episódios depressivos; F41 - outros transtornos ansiosos; F33 transtorno depressivo recorrente. 
O total ano a ano revelou uma queda no início da série, quando chegou a $13.533 \mathrm{em}$ 2010, voltando a subir até atingir o maior valor da série em 2015, com 17.788. A partir daí, uma leve oscilação para menos fez com que o total desses quatro agravos atingisse 16.110 notificações em 2017. Cumpre destacar que a série mostrou um acúmulo de 159.063 notificações dos quatro agravos, sendo que 84.022 (50,31\%) foram de reações graves ao stress, seguido pelos episódios depressivos, com 37.291 (23,44\%), outros transtornos ansiosos, com 27.492 (17,28\%) e transtorno depressivo recorrente, com 10.258 (6,45\%). Portanto, o stress não só ocupa a primeira posição entre os agravos de saúde mental relacionados ao trabalho, como representa um acúmulo de notificações maior que os outros três juntos.

Convém fazer a ressalva, conforme Dejours (1992), que a saúde mental é complexa e com limites tênues entre os possíveis diagnósticos, assim como entre os seus nexos causais, tanto os da dinâmica própria do trabalho quanto os da reprodução social em geral, embora se deva reconhecer a centralidade daquela para a constituição dessa. Por tais razões, é mais fecundo olhar para a totalidade da relação dialética que, para o autor, constitui-se entre prazer e sofrimento pelo trabalho do que, pura e simplesmente, para doenças ou transtornos isoladamente.

Nessa esteira interpretativa, partimos do stress como mediação para pensar, mais amplamente, a saúde mental dos trabalhadores, inclusive ratificando a eminência dessa mediação ante o conjunto que compõe. As várias formas de sofrimento mental devem, ainda, servir para caracterizar os padrões de desgaste mental dos trabalhadores (SELIGMANNSILVA, 2011), refletores da articulação antagônica entre as forças produtivas e as relações sociais de produção (LAURELL; NORIEGA, 1989), exponenciadas com a reconfiguração produtiva.

A categoria teórica do desgaste foi inserida no debate da Saúde do Trabalhador por Laurell e Noriega (1989), com fins de refletir o caráter geral da saúde face ao modo de produção capitalista. o padrão de desgaste, nessa formulação, é resultado da interação dinâmica das cargas de trabalho - as de materialidade interna: físicas, químicas, biológicas e mecânica; e as de materialidade externa: fisiológicas e psíquicas. 
Todas essas cargas, ao interagirem entre si, são relevantes à psicodinâmica do trabalho (SELIGMANN-SILVA, 2011), gerando padrões de desgaste mental. Não obstante, as cargas psíquicas assumem contornos mais decisivos nessa seara, sobretudo considerando as metamorfoses do complexo do trabalho. Consoante vimos na literatura revisada, podemos exemplificar essas cargas pelos elementos estressores identificados, a exemplo da sobrecarga de trabalho, prazos curtos para cumprimento de tarefas, problemas interpessoais no trabalho, falta de condições estruturais, entre outras. Cumpre recuperar, também, que essas cargas podem ser mais potentes para determinadas profissões (como no setor saúde ou bancário) ou grupos (a exemplo das mulheres), mas agora podendo as entender no interior de um processo de determinação social, regido, conforme defendemos, pelas respostas à crise estrutural do capital.

Por fim, tal processo pode, ainda, ser considerado em graus maiores de totalidade, tomando-se a saúde mental dos trabalhadores como particularidade da questão da saúde dos trabalhadores em termos universais (SOUZA, 2019). Particularmente no Brasil, o processo é ainda mais aviltante, tendo em vista desigualdades forjadas em meio a um capitalismo do tipo dependente e sua peculiar superxeploração da força de trabalho (ANTUNES; PRAUN, 2015).

\section{NOTA REFLEXIVA FINAL}

A nota reflexiva final consiste em apreender um outro componente desse prolixo mosaico, qual seja: o desmonte e a fragilização dos serviços públicos de saúde no Brasil. É importante considerar que o Sistema Único de Saúde (SUS) há tempos sofre com as medidas neoliberais adotadas no âmbito econômico-político, marcando a faceta dependente do processo de mundialização do capital pela derruição das políticas sociais. No caso do SUS, esse processo se manifesta desde o seu subfinanciamento até a descaracterização de sua estrutura.

No caso da Saúde Mental, a contraofensiva da perspectiva manicomial colocou sob risco as conquistas da Reforma Sanitária e, consequentemente, fragilizou a Rede de Atenção Psicossocial (Raps), a partir da qual haveria um horizonte mais fecundo de enfrentamento 
dos problemas psicoemocionais e, até mesmo, com vistas à promoção da saúde mental, o que seria fulcral em face do stress.

Em se tratando de Saúde do Trabalhador, observou-se um processo de institucionalização na contramão da perspectiva que orientou o SUS. Ora, se na Reforma Sanitária foi reconhecida a centralidade da categoria trabalho para a saúde, a implementação do sistema não efetivou essa condição, colocando à margem, exatamente, aquele campo que toma por base a relação trabalho-saúde.

A tragédia da saúde mental dos trabalhadores brasileiros se manifesta, portanto, pelo menos, em duas faces: de um lado, a degradação da saúde mental pelo trabalho e, doutro, a exponenciação por conta da fragilização das políticas de saúde no Brasil. Em meio a esse complexo processo, o stress relacionado ao trabalho se revelou uma potente mediação para entendê-lo.

\section{REFERÊNCIAS}

ALVES, G. Trabalho, corpo e subjetividade: toyotismo e formas de precariedade no capitalismo global. Trabalho, educação e saúde, Rio de Janeiro, v. 3, n. 2, p. 409-428, 2005.

ALVES, G. 0 novo (e precário) mundo do trabalho. Reestruturação produtiva e crise do sindicalismo. $1^{\text {a }}$ ed. São Paulo: Boitempo, 2010.

ANTUNES R. Adeus ao trabalho? Ensaio sobre as metamorfoses e a centralidade do mundo do trabalho. São Paulo: Cortez, 2015.

ANTUNES, R.; PRAUN, L. A sociedade dos adoecimentos. Serviço Social \& Sociedade, Rio de Janeiro, n. 123, p. 407-427, 2015.

AREIAS, M. E. Q.; GUIMARÃES, L. A. M. Gênero e estresse em trabalhadores de uma universidade pública do estado de São Paulo. Psicologia em estudo, Maringá, v. 9, n. 2, p. 255-262, 2004.

BARROS-DELBEN, P.; PEREIRA, G. K.; MELO, H. M.; THIEME, A. L.; CRUZ, R. M. Mapeamento de Estressores no Trabalho de Expedicionários do Programa Antártico Brasileiro (PROANTAR). Psicologia: Teoria e Pesquisa, Brasília, v. 35, e3559, 2019.

CCVISAT. Transtorno mentais relacionados ao trabalho no Brasil 2006-2017. Boletim epidemiológico, Salvador, v. 13, n. 9, p. 1-5, 2019.

CHESNAIS, F. Mundialização: o capital financeiro no comando. Revista Outubro, v. 5, p. 7-28, 2001.

DEJOURS, C. A loucura do Trabalho: estudo de psicopatologia do trabalho. $5^{\mathrm{a}}$ ed. São Paulo: Cortez, 1992. 
ENGELS, F. A Situação da classe trabalhadora na Inglaterra. São Paulo: Boitempo, 2008.

FADEL, C. B.; FLORES, M. T.; BRIGOLA, S.; ZANESCO, C.; BORDIN, D.; MARTINS, A. S. Processo de trabalho e disposição ao stress entre docentes de ciências biológicas e da saúde. Revista de pesquisa cuidado é fundamental, Rio de Janeiro, v. 11, n. 4, p. 843-848, 2019.

FARO, A.; PEREIRA, M. E. Raça, racismo e saúde: a desigualdade social da distribuição do estresse. Estudos de Psicologia, v. 16, n. 3, p. 271-278, 2011.

FERREIRA, J. S.; RIBEIRO, K. V.; CARAMURU, O. S.; HANZELMANN, R. S.; VELASCO, A. R.; PASSOS, J. P. Stress and coping strategies in workers of nursing of a family health unit. Revista de pesquisa cuidado é fundamental, Rio de Janeiro, v. 9, n. 3, p. 818-823, 2017.

FONTES, V. Capitalismo em tempos de uberização: do emprego ao trabalho. Marx e o Marxismo, Niterói, v. 5, n. 8, p. 45-67, 2017.

GEREMIAS, L. M.; EVANGELISTA, L. F.; SILVA, R. C.; FURTADO, D. S.; SILVEIRA-MONTEIRO, C. A.; FREITAS, C. F. Prevalência do diabetes mellitus associado ao stress ocupacional em trabalhadores bancários, Minas Gerais, Brasil. Revista cuidarte, Bucaramanda, v. 8, n. 3, p. 1863-1874, 2017.

JACQUES, J. P. B.; RIBEIRO, R. P.; SCHOLZE, A. R.; GALDINO, M. J. Q.; MARTINS, J.T.; RIBEIRO, B. G. A. Wellness room as a strategy to reduce occupational stress: quasi-experimental study. Revista Brasileira de Enfermagem, Brasília, v. 71, suppl 1, p. 483-489, 2018.

LLAPA-RODRIGUEZ, E. O.; OLIVEIRA, J. K. A.; LOPES NETO, D.; GOIS, C. F. L.; CAMPOS, M. P. A.; MATTOS, M. C. T. Stress ocupacional em profissionais de enfermagem. Revista enfermagem UERJ, Rio de Janeiro, v. 26, e19404, 2018.

LAURELL, A. C.; NORIEGA, M. Processo de Produção e Saúde: Trabalho e desgaste operário. São Paulo: Hucitec, 1989 .

LESSA, S. Notas sobre a historicidade da essência em Lukács. Novos Rumos, Marília, v. 30, p. 22-30, 1999.

LOPES, S. V.; SILVA, M. C. Stress ocupacional e fatores associados em servidores públicos de uma universidade federal do sul do Brasil. Ciência \& Saúde Coletiva, Rio de Janeiro, v. 23, n. 11, p. 3869-3880, 2018.

LUKÁCS, G. Para uma ontologia do ser social I. São Paulo: Boitempo, 2012.

MARGIS, R.; PICON, P.; COSNER, A. F.; SILVEIRA, R. D. O. Relação entre estressores, stress e ansiedade. Revista de psiquiatria do Rio Grande do Sul, Porto Alegre, v. 25, supl.1, p. 65-74, 2003.

MARX, K. O Capital: crítica da economia política. Livro primeiro, Tomo I. $3^{\mathrm{a}}$ ed. São Paulo: Nova Cultural, 1988a.

MARX, K. O Capital: crítica da economia política. Livro primeiro, Tomo II. $3^{\mathrm{a}}$ ed. São Paulo: Nova Cultural, 1988b.

MARX, K. Contribuição à crítica da economia política. $2^{\mathrm{a}}$ ed. São Paulo: Expressão Popular, 2008.

MÉSZÁROS, I. Para além do Capital: rumo a uma teoria da transição. São Paulo: Boitempo, 2009.

MUNIZ, M. F.; MUNIZ, F. W. M. G.; RODRIGUES, L. K. A.; OLIVEIRA, M. B. L.; BARROS, I. D.; CARVALHO, R. S. Fontes de stress, bem-estar psicológico e saúde entre estudantes de Odontologia: uma comparação entre fases préclínica e clínica e entre os sexos. Revista da ABENO, Porto Alegre, v. 19, n. 3, p. 2-12, 2019.

ORGANIZAÇÃO MUNDIAL DA SAÚDE. Saúde Mental: nova concepção, nova esperança. Lisboa: OMS, 2002.

PASQUALUCCI, P. L.; DAMASO, L. L. M.; DANILA, A. H.; FATORI, D.; LOTUFO NETO, F.; KOCH, V. H. K. Prevalence and correlates of depression, anxiety, and stress in medical residents of a Brazilian academic health system. BMC Medical Education, California, v. 19, n. 193, p. 1-5, 2019. 
PINTO, G. A. A organização do trabalho no século 20: taylorismo, fordismo e toyotismo. $2^{a}$ ed. São Paulo: Expressão Popular, 2010.

PIZUTTI, L. T.; CARISSIMI, A.; VALDIVIA, L. J.; ILGENFRITZ, C. A. V.; FREITAS, J. J.; SOPEZKI, D. et al. Evaluation of Breathworks' Mindfulness for Stress 8-week course: Effects on depressive symptoms, psychiatric symptoms, affects, self-compassion, and mindfulness facets in Brazilian health professionals. Journal of clinical Psychology, Hoboken, v. 75, n. 6, p. 970-984, 2019.

RIBEIRO, R. P.; MARZIALE, M. H. P.; MARTINS, J. T.; GALDINO, M. J. Q.; RIBEIRO, P. H. V. Stress ocupacional entre trabalhadores de saúde de um hospital universitário. Revista gaúcha de enfermagem, Porto Alegre, v. 39, e65127, 2018.

SANTANA SILVA, A. D.; LEITE RIOS, O. F.; FRANÇA-BOTELHO, A. C. Presencia de estrés y otros factores de riesgo de enfermedad cardiovascular entre las enfermeras y abogados de una ciudad de Minas Gerais - Brasil. Cultura de los cuidados, Alicante, v. 21, n. 49, p. 173-180, 2017.

SANTOS, A. M.; CASTRO, J. J. Stress. Análise Psicológica, Lisboa, v. 4, n. 16, p. 675-690, 1998.

SELIGMANN-SILVA, E. Trabalho e desgaste mental: o direito de ser dono de si mesmo. São Paulo: Cortez, 2011.

SOUZA, D. O.; MELO, A. I. S. C.; VASCONCELLOS, L. C. F. A saúde dos trabalhadores em "questão": anotações para uma abordagem histórico-ontológica. O Social em Questão, Rio de Janeiro, v. 18, n. 34, p. 107-136, 2015.

SOUZA, D. O. Saúde do(s) trabalhador(es): análise ontológica da "questão" e do "campo". Maceió: Edufal, 2019.

TONET, I. Método científico: uma abordagem ontológica. São Paulo: Instituto Lukács, 2013.

(c) EY

Este trabalho está licenciado com uma Licença Creative Commons - Atribuição 4.0 Internacional. 